International Journal of Language Education

Volume 5, Number 4, 2021, pp. 296-308

ISSN: $2548-8457$ (Print) 2548-8465 (Online)

Doi: https://doi.org/10.26858/ijole.v5i4.19482

\title{
Motivational currents of Indonesian postgraduate students studying abroad
}

\author{
Rasman Rasman \\ Universitas Negeri Yogyakarta, Indonesia \\ Email:asman@uny.ac.id
}

Received: 3 March 2021

Reviewed: 1 August 2021-30 October 2021

Accepted: 5 December 2021

\begin{abstract}
Motivational currents, a relatively new concept in the field of language learning, has contributed to understanding how long-term motivational energy can be sustained among learners. Despite such critical contribution, little is known on how one of its core elements called vision, a vivid image of one's future self, can be sustainable in such a long period. This has resulted in the difficulty for teachers to create motivational currents among their learners. This article aims at contributing to the understanding of the dynamic nature of vision in the phenomena of motivational currents. It reports on a Retrodictive Qualitative Modelling (RQM) study conducted using complex dynamic system's frame. The data were gathered from Indonesian postgraduate students studying in a university in the United Kingdom using introspective, semistructured interview and self-assessed motivational trajectory. They were then analyzed using Interpretative Phenomenological Analysis (IPA). The findings show that the participants experienced motivational currents although their visions or images of their future selves were slightly changing during the period. The findings will then be discussed with regards to the nature of interconnectedness between the motivational currents system and the self-system. The article is ended by outlining some pedagogical implications as well as recommendations for future research.
\end{abstract}

Keywords: Motivational currents; vision; complex dynamic system.

\section{Introduction}

Motivation in second language learning has now been seen from its dynamic aspect. Learners' motivation is fluctuating due to the influence of multiple factors such as personal, contextual, and social. In fact, for language teachers, unstable motivation among learners might not be a surprising phenomenon.

This changing perspective has motivated many researchers to find methods for creating an enduring motivation in the classroom. To address this problem, the concept of 'Directed Motivational Currents' (DMCs) was introduced (Dörnyei, 2020). In these phenomena, the enduring nature of vision creates an intense motivational pathway that is relatively sustainable. By having a vivid image of their future selves, learners would be able to focus all of their energy to achieve their goal. Also, in this period the multiple factors that may lower the motivation are overridden by the currents.

The typical example of DMCs is a learner preparing for a trip to a foreign country. Because

of his vision of becoming a fluent speaker, he focuses his attention to doing activities related to 
the learning of the foreign language such as memorizing vocabularies, enrolling in a language course, etc. He is so focused in achieving the goal that he even refuses to attend his friends' social invitation or other activities.

However, on the other hand, the notion that vision itself is enduring and stable is being questioned. You and Chan (2015), for instance, found in their study that learners' mental imagery is not fixed, it continuously changes during the $\mathrm{L} 2$ learning because during the learning process, learners would encounter many challenges that may affect how they imagine themselves in the future. This raises a question on how DMC could be relatively stable if their component is unstable. Without knowing clearly whether this instability of its element affects the overall currents and how to handle this dynamic change, all efforts to create DMCs in the classroom might be doomed to failure.

Beside attempting to validate the phenomena, this study is also a preliminary effort at examining the dynamic nature of vision in the relatively stable motivational currents. Focusing on Indonesian students' motivational experience in preparing to study in the UK, the researcher found two participants having experienced the phenomena. During the DMC phenomena, they experienced changes in possible selves. The theoretical explanation and pedagogical implication of this finding are discussed.

\section{Literature review}

Motivation and complex dynamic system theory

Motivational theory in language learning has gone through several phases. Gardner and Lambert (1972) initiated the social psychological period focusing on the attitude towards the language and the language community as the source of motivation. In the 1990s, the popularity of cognitivist approach in psychology marked the educational psychology period with the selfdetermination theory (Ryan \& Deci, 1985) and attribution theory (Weiner, 1992) as the major theories. In the turn of the century, motivation shifted to the process-oriented period, perceiving motivation as a process (Dörnyei \& Ottó, 1998). These three periods still concern with cause-effect relationships between variables in researching motivation. With the emergence of the fact that learners' fluctuated motivation is influenced by multiple factors interacting in a non-linear way, motivational theory arrives at the latest phase, adopting the Complex Dynamic System Theory (CDST) (Dörnyei \& Ryan, 2015; Hiver \& Larsen-Freeman, 2020). This is also triggered by the trend of adopting CDST (Larsen-Freeman \& Cameron, 2008; Hiver \& Papi, 2020) in the field of SLA.

The two basic principles of CDST, which are particularly relevant to this study, are stability and variability. Larsen-freeman and Cameron (2008) revealed that although complex system may arrive to a point of stability, the system is still continually changing because of the interactions with other interconnected systems. She further argued that in applying CDST to applied linguistics, stability and variability are two key elements that can shed light of the learners' development in language learning. Both inside system and outside system needs to be considered to understand a phenomenon holistically (Larsen-freeman, 2012). The stronger the stability of the system, the more likely it turns into its stability despite the other system's influence. For example, teachers may have perceived their students have had a stable motivation. However, then they are surprised seeing their students' motivation dropped instantly. In this case, they apparently lose sight on the background system that continually influences their students' motivation. By knowing the interplay of the background systems, teachers might be able to anticipate the decrease of motivation by, for instance, creating more positive learning environments (Mercer, 2014). 
Directed Motivational Currents

A DMC is a surge that overrides the various factors that potentially inhibits one's motivation (Dörnyei et al., 2015; Dörnyei, 2020). This motivational current's power is higher than that of usual high motivation phenomena (Dörnyei et al., 2016). In the DMCs, Vision, as the highest order of motivational force (Dörnyei and Kubanyiova, 2014), is seen as the primary element because it creates a specific goal with a vivid image of our future self. It is the final destination to which all energy is directed. This goal then influences someone to have a salient/facilitative structure, the structured behavior performed in a regular basis until it becomes almost self-propelling motivation or to borrow Dörnyei's (2016) word, 'motivational autopilot'. Positive emotionality is one of the key components of DMCs since it intensifies the surge with pleasurable feeling if they accomplished the goals which override the negative feeling brought about by the tasks they are doing. These three components are unified into one single powerful motivational current.

To validate these three core elements, Henry et al. (2015) conducted the first empirical study on DMCs, focusing on migrant learners studying Swedish in Sweden. The result showed that those three elements were present. This empirical study has established the DMC as a solid theory of L2 motivation.

Although DMC construct has been researched and validated in terms of the existence of its three core elements, there is a lack of explanation on how one can have a vivid vision that enables him to experience a DMC phenomenon despite the multiple factors that may interplay particularly with regards to the self-system, the closest system that shapes vision. The explanation that vision is the highest order factor in this phenomenon, and thus it can override multiple factors, apparently does not really fit with the current adaptation of CDST where dynamic relationships and interconnectedness between system is emphasized (Larsen-Freeman \& Cameron, 2008; LarsenFreeman, 2018). Even if in DMC, vision is indeed static, there should be an explanation of why vision consistently becomes a strong attractor in this complex system. Thus, there is a need to examine the dynamic nature of vision with regards to the changing of possible selves in this relatively stable period of motivational currents.

The dynamics of vision and possible selves

Vision is closely associated with possible selves (Markus \& Nurius, 1986) because, as explained by Dörnyei and Kubanyiova (2014), possible selves include the image and sense of ourselves. It means that our vision is the mental imagery of our working possible selves.

Current studies about possible selves conclude that possible selves are not static. Henry (2015) argued that changes of future self-guides is the result of the interaction with other selfconcepts. It means that the working possible selves will change from time to time depending on the interaction with the other possible selves. You and Chan's (2015) study on the dynamic nature of imagery and possible selves of 228 Chinese students confirms that both are dynamically changing, not fixed targets. Similarly, Mercer's (2015) multilevel nested study, focusing on the dynamic of the self in EFL learners of Austrian University, revealed that learners' self-system was changing, and this changing was unique from one learner to another. In the field of psychology, Strahan and Wilson (2006) studied the interaction between past, present, and possible future selves. Drawing from the Markus and Nurius' (1986) study, they argued that under particular circumstances, possible selves are influenced by past selves. These findings show that possible selves are very dynamic, constantly interacting with their environments. It implies that vision as the image attached to the possible selves is also unlikely not to experience changes. Such 
investigations on the dynamic nature of vision is understandable because everything from the perspective of complex theory that is defined as a static being will be irrelevant.

The previous studies on the dynamic nature of imagery, possible selves, or self-concept in general, thus, motivate this study which focused on the dynamic of learners' image of their future selves in the DMC phenomena. While the previous works on the dynamic of possible selves were carried out during the fluctuated period of motivation, this study distinctively examined the instability of possible selves within the relatively stable motivational currents.

\section{Research method}

\section{Contexts}

This study involved Indonesian postgraduate students studying in a university in the United Kingdom. The study focused on their motivational experiences in learning English in Indonesia which had helped them secure a place in the university. They were successful not only in securing their place to study in the university, but also in getting the Indonesian government's full scholarship which tightly requires them to go through several selections, including passing IELTS test.

\section{Research questions}

1. Can DMC phenomena experiences be found among these Indonesian postgraduate students?

2. If the DMC phenomena are found, do they also experience changes in possible selves during that period?

\section{Participants}

This study used critical case sampling (Dörnyei, 2007) where the researcher purposively chose salient participants that would best represent the phenomena. I chose five Indonesian postgraduate students regarded as highly motivated participants based on my observation as part of the community. The selection of these participants did not aim to represent the population because the aim of this research was to investigate the phenomena in the particular context. According to Larsen-Freeman (2008), the purpose of the research under complexity theory is only to find 'particular generalizations, not universal ones' (p. 235). However, it does not mean that the findings of one context would be irrelevant to other contexts. Similar findings from one context to another can be useful to find out 'the possibility of connected emergent outcomes' (p. 236).

I contacted them to participate voluntarily and informed them about the confidentiality of the data. They all agreed to participate in the study. Two focal participants discussed in the study were Teresa (25) and Maria (24) (Pseudonym), who, at the time of the data collection, were doing their master's in the same university in 2015. Before being a postgraduate student majoring social policy, Teresa had worked at Indonesia's national commission for child protection for one year. She applied for the university and scholarship in the same year of her intake of study. Meanwhile, Maria, who were taking English education as her major, had prepared her application for more than a year before finally getting into her dream university. Furthermore, she spent her time studying in the intensive English course for five months after quitting from her job as a teacher.

\section{Approach and method}

Based on the complex system approach (Larsen-Freeman, 2008; Larsen-Freeman, 2018), the relationships between variables are non-linear. There would be multiple factors interacting to each other before emerging into a particular outcome. Therefore, a research on DMC is more 
operationalized by reversing the traditional way of researching using Retrodictive Qualitative Modelling (RQM) (Dörnyei, 2014; Hiver \& Al-Hoorie, 2020). As its name suggests, the method employed in this research initially identified the outcomes, and then, the researcher traced back to find out the interconnectedness of this DMC system and the self-system.

Instruments

In this study, two instruments were used simultaneously as they were completing each other. The self-plotted graph, the first instrument, has previously been used in some studies focusing on the dynamic motivational phenomena (Henry et al., 2015).

The second instrument, semi-structured interview, was used to help the researcher gain deeper relevant information about the phenomena under study (Dörnyei, 2007). Interview guides used in the interview were adapted from You and Chan's (2015) study with some changes. Before the interview, a piloting was carried out to ensure that the interview guides and prompts were working (Brinkmann \& Kvale, 2015). The questions were not asked in the exact same order nor in the exact same words in the interview. Since retrospective interview depends on the participants' memory of the past events, I focused on eliciting particular events and asking specific examples (Ericcson \& Simon, 1980).

Data analysis procedure

Interpretative Phenomenological Analysis (IPA) (Smith \& Osborn, 2008) was the most suitable data analysis for the study concerned on the meaning making of certain phenomena. I attempted to make sense the way the participants make sense of their experience.

After transcribing the interview data, I read them multiple times to familiarize with the data (Smith \& Osborn, 2008) while also looking at self-assessed graph to identify three components of DMCs: vision, salient/facilitative structure, and positive emotionality. Once DMC phenomena were found, the transcripts were read again three additional times which aimed to find if there were any changes of the possible selves during the DMC phenomena. Then, emerging pattern of dynamic relationships among the possible selves and between possible selves and the DMC system were investigated.

\section{Finding and discussion}

Maria's and Teresa's motivational currents

Two focal participants, Maria and Teresa (pseudonym), have experienced DMC phenomena. It can be seen from the existence of two fundamental criteria of DMCs (Henry et al., 2015): a distinct period of high motivation in their motivational trajectory graph and its descriptions as revealed in the interview data.

Teresa revealed her intense motivation in learning English happened during the period of February-June 2015, when she was studying IELTS as a preparation for studying abroad.

"This time is the time when I learned English in the small focus group. So, I feel very motivated to learn English during this period and I used focused group discussion to get the score. And then after I get the letter of acceptance, and I got the scholarship, it's like a flat..." (Teresa)

After this period, she admitted that 'it's like a flat' and the energy was no longer as intense as before. This is in accordance with the characteristic of experiencing DMC phenomenon that "once the main goal has been achieved, the current will cease" (Dörnyei et al. 2015, p. 98). 


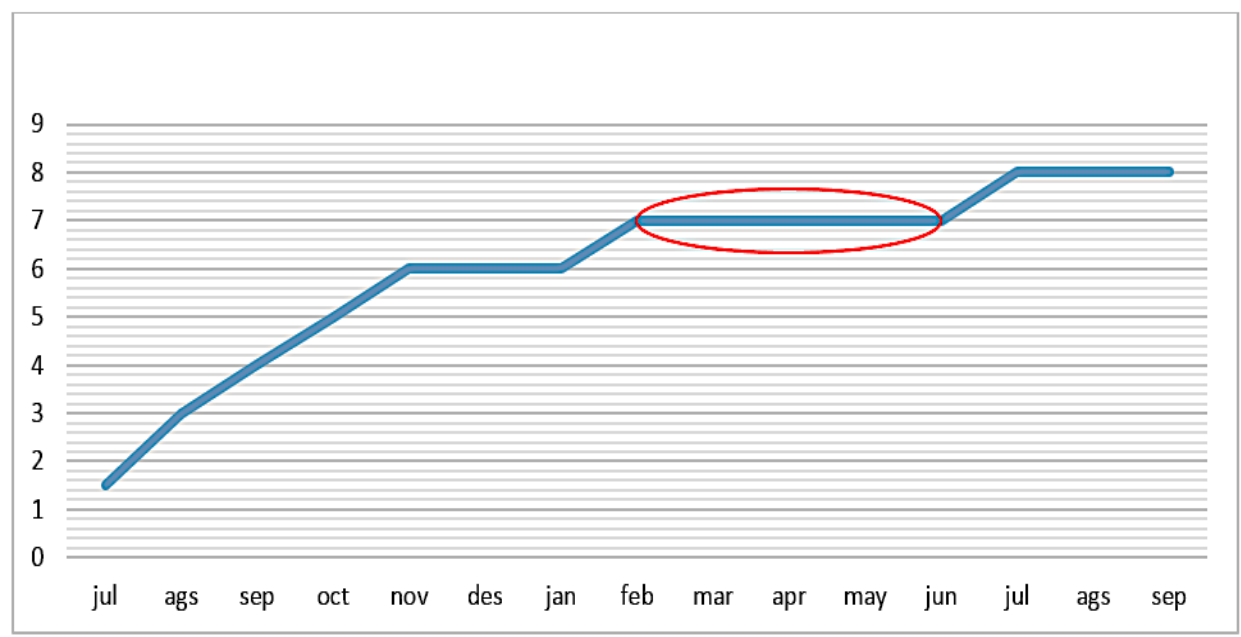

2015

Figure 1. Teresa's Self-Assessed Motivational Trajectory

Although there seems to be an increase in the level of motivation in the following period (June-September), this period was described as 'flat'. It appears to be consistent with the Dörnyei et al. (2016) explanation that DMCs is different from high motivation in the sense that not all motivated periods can be regarded as a DMC.

Three core elements of DMCs are also found during this period. Teresa's vision was to study in the UK where she could communicate and interact with other international students with fluent English.

"I just imagined myself at that time, that I can show my English ability which is the level of good or even great." (Teresa)

The salient/facilitative structure, DMC element indicated by doing routine activities to achieve the goal, also appeared. To achieve her desired IELTS score, she made a discussion group with her friends, and met with them three times a week in a regular basis. Lastly, positive emotionality was also confirmed, evidenced by her feeling of satisfaction when she made improvements.

"Yeah, I'm satisfied enough because I could pass IELTS in once because the other friends just told me that, okay, you have to take the test two or three times, because you usually would just get 6 for the band scores. And when I just tried the first time, and then I just passed with the 6.5." (Teresa)

Similar to Teresa, Maria's period of intense motivation was also started when she was studying IELTS. Unlike Teresa, she enrolled in IELTS preparation course for 5 months, devoting most of her time to focus on improving her score. She felt as if all energy was flowing to accomplish her goal.

"IELTS was taking my time. I didn't have any time for other activities" (Maria)

She even decided to resign from her job as a teacher in order to be more focused. 
"... I was asking the permission from the headteacher to quit the jobs to pursue master degree. Actually, she continuously asked me to continue working there, but I said I had another goal, another target." (Maria)

During this period, she could imagine her future self vividly as a postgraduate student studying in the classroom with the qualified lecturers.

"I saw myself in the future that I would be taught by lecturers who have very good qualifications, professional lecturers and all learning service are complete, and I'm becoming more challenged because I would be given challenging tasks. "(Maria)

Moreover, she also added that she was able to elaborate her desire to have an interaction with other classmates, especially the native speakers of English.

"I see myself entering a classroom to study with other English native speaker students, and the lecturers are very professional, smart, and then I can practice my English everyday with the real English native speakers..." (Maria)

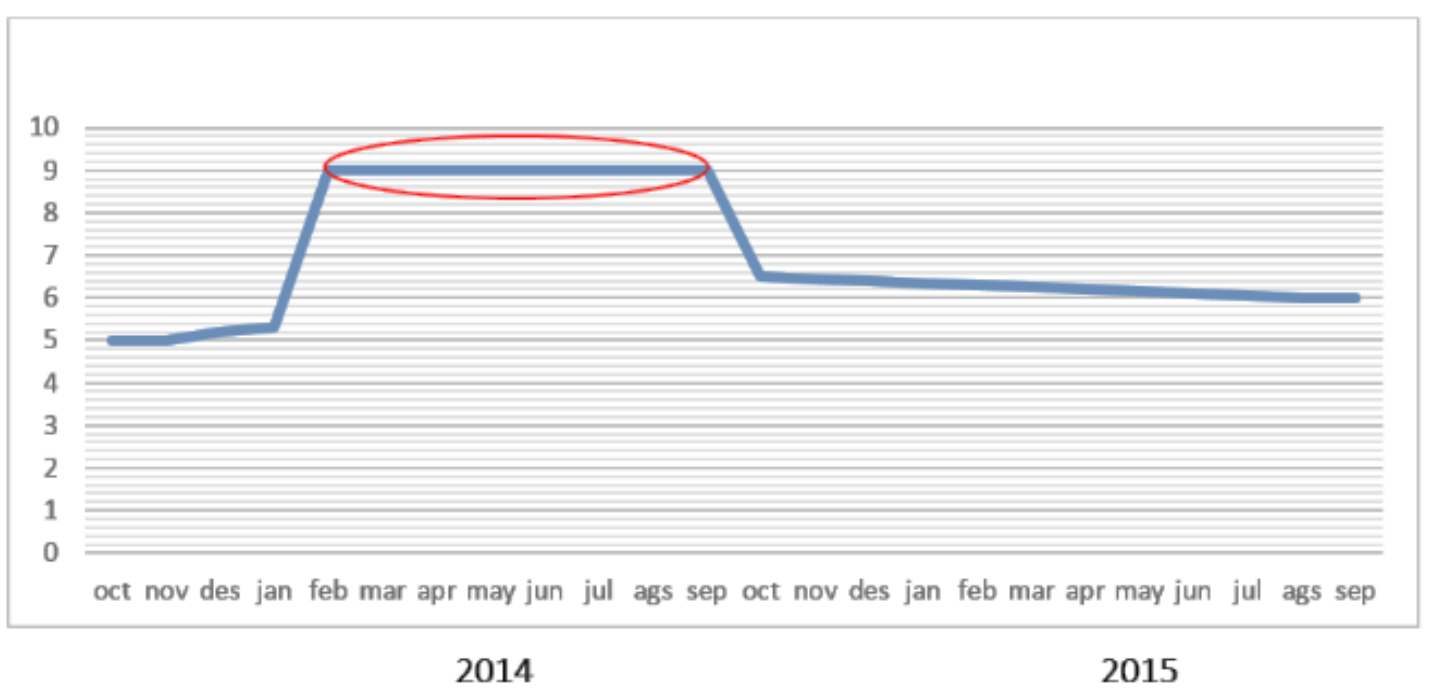

Figure 2. Maria’s Self-Assessed Motivational Trajectory

The salient/facilitative structure could be indicated from her daily schedule of learning English. For five months, she chose to live away from her family because the intensive IELTS course that she took is located in another island in Indonesia. In this course, she learned English day and night.

“...I took intensive IELTS preparations guided by a teacher. The class started from 5 a.m. until 12 a.m." (Maria)

Although she admitted that the course was quite depressing, she still maintained her positive emotionality to carry on with the task. Indeed, as Dörnyei et al. (2015) said, the positive emotionality does not mean the task is pleasurable in itself but rather, it is because by doing this 
task, the feeling of closer to the goal is getting bigger, thus, there is a positive attitude in facing the challenge.

"Well sometimes I was crying because of this depressing. But if I don't do this, if I stop from this, all my dreams would be lost." (Maria)

According to Dörnyei et al. (2015), unlike ordinary motivational flow (Csikzentmihalyi, 1990) where the enjoyment is only in one specific task, DMCs provide overall enjoyment of the feeling of being closer to the goal.

These findings are in accordance with Dörnyei's et al. $(2013,2015)$ conception that DMC consists of three core elements. Unlike Henry's et al. (2015) first empirical study on DMCs that was participated by language learners in a foreign country, this study was situated in the learners' own country. So, these findings not only validate the DMCs phenomena but also contribute to the attempt to shed light of another possible setting of DMC phenomena.

The dynamics of Maria's and Teresa's possible selves during DMC phenomena

Although Teresa's and Maria's visions of their ideal self was apparent in their motivational currents, the interview data revealed that both also experienced shift of visualization about their possible selves.

For Maria, her feared self of not being able to reach the goal was activated when she didnot get the score she wanted in the first test. The people's comments on her failure apparently act as another self-relevant events influencing this change.

“... I also took my first IELTS here and I failed. And I felt a bit unmotivated. People suggested me to stop taking IELTS but then, I decided to continue my study." (Maria)

However, despite these undesirable results, she then continued to study and got the score she wanted in the next test. It appears that her feared self was only working in a short period before the vision of her ideal self was reactivated. One of the reasons she could increase her motivational intensity again was apparently her awareness of the reasons why she failed and her image of herself as the person who had the capacity to conquer the test.

"Well, I knew the factors, I knew the causes why I failed. I knew exactly what I should do to fulfill the criteria so that I could get the score that I wanted.." (Maria)

Similar to Maria, Teresa also experienced change of her possible selves. She was temporarily afraid of not being a successful English speaker in her classroom.

"I just expected myself becoming more fluent in English, and um, I didn't want to get bad opinion from lecturers or from friends about Indonesian skill of English...” (Teresa)

She experienced this fear after she realized she would be the only Indonesian in the classroom. However, she then could reactivate her ideal L2 self by changing her perspective, seeing the situation as the opportunity to show her ability in using English. 
"I just imagined myself at that time, that I can show my English ability which is the level of good or even great." (Teresa)

This dynamic aspect of the change in possible selves is contrasted to their overall intense motivational currents that are relatively stable. The possible explanation why this happened is because, as Dörnyei (2020) explained, DMCs are able to override multiple factors to align with the currents to get into the direction set up by vision. Thus, during these phenomena, Maria and Teresa seem to perceive their fear selves temporarily as the barrier but in a relatively short time they could use it as a source of motivation/feedback to do better.

Vision in the motivational currents: A dynamic element in the stable system

The major finding of this study was that dynamic change of possible selves can be found in a seemingly stable period of motivational currents. Looking from the longer timescale, DMCs are perceived as a stable motivational period. However, if this period is divided into smaller timescales, the dynamic interactions of its elements are apparent.

In the case of Maria and Teresa, the period between when they started learning IELTS until they achieved their desired score can be regarded as the stable period. However, if this period is divided into smaller timescales within their DMC experiences, it can hardly be seen as a stable period. Looking a phenomenon at different timescale is important because as de Bot (2015) puts it, '... looking at one timescale only may block our view on the larger picture of phenomena on different timescales' (p. 36). Figure 3 provides the illustration on how the instability can apparent in the relatively stable DMC phenomena in the smaller timescale. Due to the nature of the retrospective study, the researcher cannot track these dynamic changes in more details. The long period of longitudinal study may help more in finding daily, weekly, and monthly changes of the possible selves. That said, it is clear that this study has shown the indication of changes of possible selves in the relatively stable motivational current phenomena.
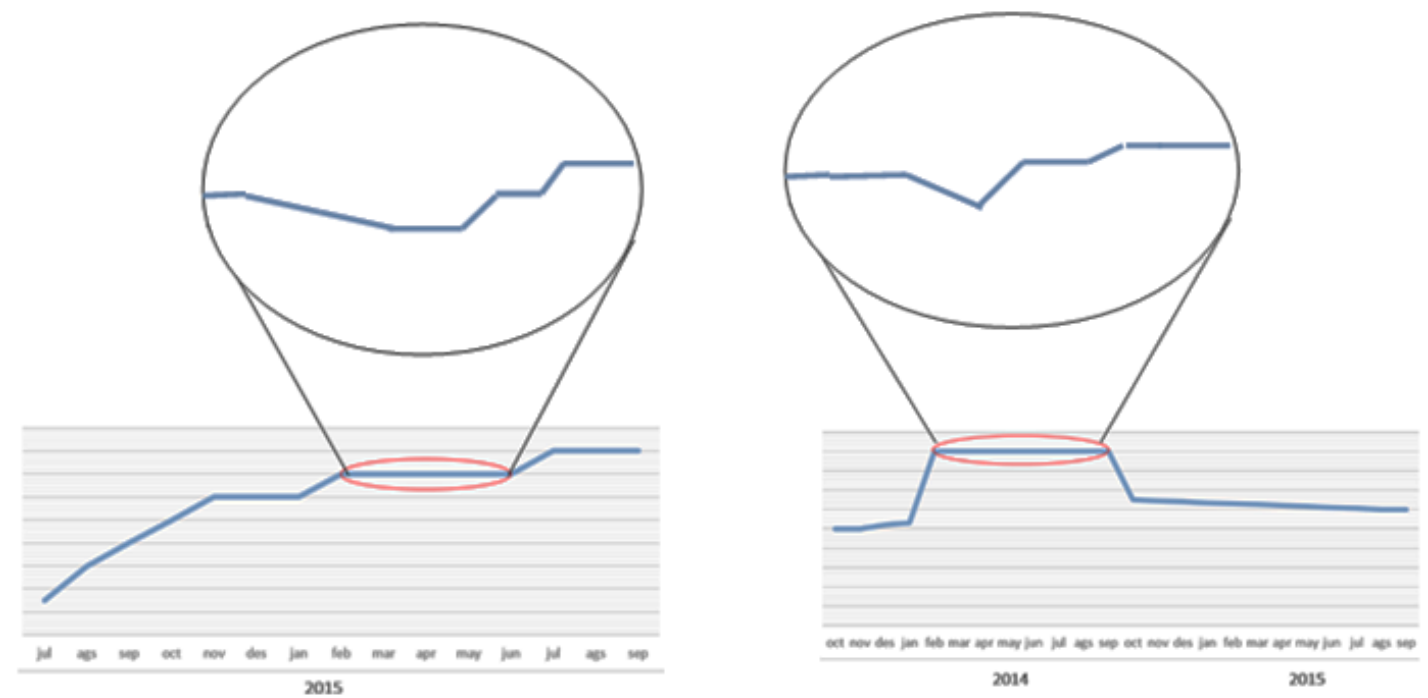

Figure 3. Illustration of Maria's and Teresa's DMC phenomena seen from different time frame.

Although there can be found fluctuation in the DMC phenomena, this finding is not inconsistent with Dörnyei's (2020) conceptualization of DMC as a stable motivational 
phenomenon. This seemingly paradox fact is apparently not unique, particularly when perceived from CDS perspective. According to Larsen-Freeman and Cameron (2008), a system can be examined through its foreground and background. A DMC as a stable phenomenon is apparently a result of foregrounding a number of focal elements in that system, which in DMC case is vision, structured behavior, and positive emotionality. Indeed, seeing the foreground of the phenomena is necessary particularly for practical reasons (Henry, 2015). However, it is important not to lose sight on the ever-changing dynamic interactions between its components in the background system. DMCs, like any other phenomena emerged from a complex system, also related to the shifting background of other relevant systems which, in the DMCs case, is apparently the selfsystem.

Self-system (including possible selves) continuously evolves as a result of adapting to the changes in the environment. These changes of possible selves in the background system of a DMC are making perfect sense because possible selves are 'most vulnerable and responsive to changes in the environment.' (Markus \& Nurius, 1986, p. 956). In the case of Maria, her ideal self of being a successful English user was vulnerable to the changing environment that was her failure in the test and the people's comments on it. Thus, her self-system adapts to this changing environment by activating her fear self. However, since the currents are so intense as a result of her vivid imagination of studying abroad, the fear self is overridden. In the case of Teresa, her ideal self as a successful English user adapted to the self-relevant event which is when she found that she would be the only Indonesian in the department. However, her intense motivation to integrate and interact with international students also seem override this fear.

\section{Conclusion}

This study has attempted to validate the DMC construct by finding the DMC phenomena in the context that has not previously been investigated. The three core elements found in this study contributes as the empirical grounding in establishing DMC construct.

In addition, focusing on the dynamic nature of vision in the DMCs, this study also found that change of possible selves appeared within the relatively stable motivational currents phenomena. This study has attempted to contribute in broadening the view of looking at DMC phenomena. Although this is a retrospective research and may have not provided more in-depth analysis of dynamic shift of the possible selves required in typical CDST-inspired research or may have offered only the partial picture of contexts and systems that interconnect to DMC phenomena, it is still noteworthy that the researcher has attempted to contribute in expanding some understanding on how the DMC system interacts with possible selves' systems. Future research would be more robust if conducted in a long term, multi-nested, longitudinal study (e.g. Mercer, 2015 ) with the focus on integrating all different interconnected system that may be relevant to the emergence of DMCs.

With regards to pedagogical implications of this study, Dörnyei et al. (2016) has proposed that DMCs can be used as a framework for focused intervention arguing and that intensive group projects for the language learners could generate DMCs. In this case, study abroad project may be a promising project to boost learners' motivation. Indonesian learners are usually very excited if they know that they would be going to other countries, particularly countries where there are native speakers of English.

The dynamic changes of possible selves found in this study does not suggest we cannot do anything to help them to have a particular possible self. However, as Mercer (2014) said, we also should not assume that we can predict or change directly the learners' possible selves. What the 
teachers have to do is to create and maintain a facilitative structure in the project because even when the learners have already in the currents, their self-system is still dynamically changing and vulnerable to the changing environment. Thus, if teachers lose sight on the development of their learners' possible selves, they might not be able to create DMCs.

Declaration of conflicting interest

The authors declare that there is no conflict of interest in this work.

Funding acknowledgement

The author received no financial support for the research, authorship, and/or publication of this article.

\section{References}

Brinkmann, S., \& Kvale, S. (2015). Interviews: Learning the craft of qualitative research interviewing (Vol. 3). Thousand Oaks, CA: Sage.

Chan, L., Dörnyei, Z., \& Henry, A. (2015). Learner archetypes and signature dynamic in the language classroom: A retrodictive qualitative modelling approach to studying L2 Motivation. In Z. Dörnyei, P.D. MacIntyre, \& A. Henry. (Eds.) Motivational dynamics in language learning (pp. 238-259). Bristol: Multilingual Matters.

Deci, E. L. \& Ryan, R. M. (1985). Intrinsic motivation and self-determination in human behaviour. New York: Plenum.

De Bot, Kees. (2015). Rates of change: timescales in second language development. In Z. Dörnyei, P.D. MacIntyre, \& A. Henry. (Eds.) Motivational dynamics in language learning (pp. 29-37). Bristol: Multilingual Matters.

Dörnyei, Z., \& Ottó, I. (1998). Motivation in action: A process model of L2 motivation. Working Papers in Applied Linguistics (Thames Valley University, London), 4, 43-69.

Dörnyei, Z. (2007). Research methods in applied linguistics. Oxford: Oxford University Press.

Dörnyei, Z. (2009). The L2 motivational self system. In Z. Dörnyei \& E. Ushioda (Eds.) Motivation, language identity, and the L2 self (pp. 9-42). Bristol: Multilingual Matters.

Dörnyei, Z. (2014). Researching complex dynamic systems: 'Retrodictive qualitative modelling' in the language classroom. Language Teaching, 47(1), 80-91.

Dörnyei, Z. (2020). From integrative motivation to directed motivational currents: The evolution of the understanding of L2 motivation over three decades. In M. Lamb, K. Csizér, A. Henry \& S. Ryan (Eds.) Palgrave Macmillan handbook of motivation for language learning (pp. 3969). Basingstoke: Palgrave.

Dörnyei, Z., \& Chan, L. (2013). Motivation and vision: An analysis of future L2 self-images, sensory styles, and imagery capacity across two target languages. Language Learning, 63(3), 437-462.

Dörnyei, Z., \& Ushioda, M. (2013). Teaching and researching motivation, 2nd ed. New York: Routledge.

Dörnyei, Z., \& Kubanyiova, M. (2014). Motivating learners, motivating teachers: Building vision in the language classroom. Cambridge: Cambridge University Press.

Dörnyei, Z., MacIntyre, P.D., \& Henry, A. (2015). Introduction: Applying complex dynamic systems principles to empirical research on L2 Motivation. In Z. Dörnyei, P.D. MacIntyre, \& A. Henry. (Eds.) Motivational dynamics in language learning (pp. 1-7). Bristol: Multilingual 
Matters.

Dörnyei, Z., Ibrahim, Z., \& Muir, C. (2015). Directed motivational currents: Regulating complex dynamic systems through motivational surges. In Z. Dörnyei, P.D. MacIntyre, \& A. Henry. (Eds.) Motivational dynamics in language learning (pp. 95-105). Bristol: Multilingual Matters.

Dörnyei, Z. \& Ryan, S. (2015). The psychology of the language learner revisited. Routldge: New York.

Dörnyei, Z., Henry, A., \& Muir, C. (2016). Motivational currents in language learning: Frameworks for focused interventions. New York: Routledge.

Ericsson, K. A., \& Simon, H. A. (1980). Verbal reports as data. Psychological Review, 87(3), 215 251.

Gardner, R. C. \& Lambert, W. E. (1972). Attitudes and motivation in second language learning. Newbury House: Rowley, MA.

Henry, A., Dörnyei, Z., \& Davydenko, S. (2015). The anatomy of directed motivational currents: Exploring intense and enduring periods of L2 motivation. The Modern Language Journal, 99(2), 329-345.

Henry, A. (2015). The dynamic of possible selves. In Z. Dörnyei, P.D. MacIntyre, \& A. Henry. (Eds.) Motivational dynamics in language learning (pp. 83-94). Bristol: Multilingual Matters.

Hiver, P., \& Larsen-Freeman, D. (2020). Motivation: It is a relational system. In A. H. Al-Hoorie \& P. D. MacIntyre (Eds.) Contemporary language motivation theory: 60 years since Gardner and Lambert (1959) (pp. 285-303). Bristol, UK: Multilingual Matters.

Hiver, P., \& Al-Hoorie, A. H. (2019). Research methods for complexity theory in applied linguistics. Bristol, UK: Multilingual Matters.

Hiver, P., \& Papi, M. (2020). Complexity theory and L2 motivation. In M. Lamb, K. Csizér, A. Henry \& S. Ryan (Eds.) Palgrave Macmillan handbook of motivation for language learning (pp. 117-137). Basingstoke: Palgrave.

Larsen-Freeman, D., \& Cameron, L. (2008). Complex systems and applied linguistics. Oxford: Oxford University Press.

Larsen-Freeman, D. (2012). Complex, dynamic systems: A new transdisciplinary theme for applied linguistics? Language Teaching, 45, 202-214.

Larsen-Freeman, D. (2015) Ten 'lessons' from complex dynamic system theory: what is on offer. In Z. Dörnyei, P.D. MacIntyre, \& A. Henry. (Eds.) Motivational dynamics in language learning (pp. 11-19). Bristol: Multilingual Matters.

Larsen-Freeman, D. (2018). Looking ahead: Future directions in, and future research into, second language acquisition. Foreign Language Annals, 51(1), 55-72.

Muir, C., \& Dörnyei, Z. (2013). Directed motivational currents: Using vision to create effective motivational pathways. Studies in Second Language Learning and Teaching, (III-3), 357-375.

Mercer, S. (2014). The self from a complexity perspective. In S. Mercer \& S. William (Eds.) Multiple perspective on the self in SLA (pp.160-176). Bristol: Multilingual Matters.

Mercer, S. (2015). Dynamics of the self: A multilevel nested system approach. In Z. Dörnyei, P.D. MacIntyre, \& A. Henry. (Eds.) Motivational dynamics in language learning (pp. 139-163). Bristol: Multilingual Matters.

Markus, H. R., \& Nurius, P. (1986). Possible selves. American psychologist, 41(9), 954-969.

Smith, J. A. \& Osborn, M. (2008). Interpretative Phenomenological Analysis. In J. A. Smith (Ed.) Qualitative psychology: A practical guide to research methods, 2nd ed. (pp. 53-80). London: SAGE Publications. 
Strahan, E., \& Wilson, A. (2006). Temporal comparisons and motivation: The relation between past, present, and possible future selves. In C. Dunkel \& J. Kerpelman (Eds.) Possible selves: Theory, research, and application (pp. 1-15). Hauppauge, NY: Nova Science.

Weiner, B. (1992). Human motivation: metaphors, theories and research. Newbury Park, CA: Sage.

You, C. \& Chan. L (2015). The dynamic of L2 imagery in future motivational self-guides. In Z. Dörnyei, P.D. MacIntyre, \& A. Henry. (Eds.) Motivational dynamics in language learning (pp. 397-418). Bristol: Multilingual Matters. 